\title{
Etkinlik Çizelgeleri: Otizmli Çocuklara Bağımsızlık, Sosyal Etkileşim ve Seçim Yapmayı Kazandırma
}

\author{
Binyamin Birkan *
}

Tohum Otizm Vakfi

$\ddot{O} z$

Etkinlik çizelgeleri, otizmli veya ileri derecede yaygın gelişim bozukluğu olan bireylerin eğitiminde kullanılan bilimsel dayanaklı etkili bir öğretim yöntemidir. Etkinlik çizelgeleri, otizmli bireylere başkalarının verdiği yönergelere bağlı kalmadan günlük etkinliklerini kendi başlarına yapmalarına yardımcı olan fotoğraflı veya yazılı ipuçlarından oluşur. Otizmli bireyler, etkinlik çizelgelerleri kullanarak rutinlerinde değişiklik yapmayl, etkinlik seçmeyi, etkinliklerini sıraya koymayı ve başkalarıla iletişime girmeyi ögrenirler. Bu makalede, ögretmen ve ebeveynlerin çocuklarının oyun, öz-bakım, sosyal etkileşim, akademik ve ev rutinlerini geliştirmek için etkinlik çizelgelerini nasıl kullandıkları, önkoşul becerilerin neler olduğu, öğretim materyallerinin nasıl hazırlandı̆̆ı ve çizelge takip becerisinin nasıl öğretildiği tartışılmaktadır.

Anahtar Sözcükler: Etkinlik çizelgeleri, otizm, otistik bozukluk, otizm spektrum bozukluğu otizmli çocukların eğitimi

\begin{abstract}
Activity schedule is a scientific based practice using to teach children with autism. Activity schedules provide photographic or textual cues that help children with autism learn to obtain materials, complete activities, and put materials away without being verbally prompted to do so. Children also learn to manage changes in routine and to choose and sequence their own activities. The article discuss prerequisite skills, preparation of teaching materials, and teachers' and parents' uses of activity schedules to promote play, self care, social interaction, pre-academic and academic skills, and home-living repertoires.
\end{abstract}

Key Words: Activity schedules, autism, autism spectrum disorder, teaching children with autism

\footnotetext{
*Doç.Dr. Binyamin Birkan, Tohum Türkiye Otizm Erken Tanı ve Eğitim Vakfi, İstanbul, E-posta: bbirkan@tohumotizm.org.tr
} 
Uygulamalı davranış analizi (UDA) oldukça geniş bir repertuarda bilimsel olarak kanıtlanmış birçok öğretim yöntemi sunar. Alan yazında, otizmli bireylerin eğitiminde bu yöntemlerin etkililiklerinin araştırıldığ 1 bilimsel dergilerde yayınlanmış 1000 'den fazla araştırmaya rastlamak mümkündür. Otizmle ilgili diğer yöntemlerin hiçbirinde böyle geniş bir bilimsel araştırma kaynağına rastlamak mümkün değildir (Eikeseth, Smith ve Jahr, 2007; Eikeseth, Smith, Jahr ve Eldevik, 2002; Gren, 1996; Howard ve diğ., 2005). Bu makalede güçlü bilimsel dayanağa sahip eğitim yöntemleri arasında sayılan etkinlik çizelgelerinin ne olduğu ve otizmli çocuklara nasıl öğretildiği örneklerle açıklanmaktadır.

Etkinlik çizelgeleri (activity schedules), Princeton Child Development Institute (Princeton Çocuk Gelişim Enstitüsü/PCDI)'da 20 yılı aşkın bilimsel çalışmalar sonucunda geliştirilmiştir (McClannahan ve Krantz, 2010). PCDI'da çalışan uzmanlar, otizmli çocukların ve yetişkinlerin birçok beceriyi öğrenebildiğini, fakat öğrendikleri becerileri çoğunlukla yetişkinin verdiği sözel ipucu, model olma ve jest-mimik ipucu olmadan sergilemediklerini gözlemlemişler ve etkinlik çizelgelerini geliştirmeye karar vermişlerdir (MacDuff, Krantz ve McClannahan, 1993; McClannahan ve Krantz 1999). Bazen çok küçük bir ipucu bile (çocuğa doğru atılan küçük bir adım ya da beklenti ile bakış) çocukların etkinliklerini yapmalarını sağlayabilir. Ancak yetişkinden gelen ipucu olmadığında, çocuklar etkinlik dı̧̧ında başka şeylerle meşgul olabilirler ya da sadece beklerler. Örneğin, 'Oyuncaklarınla oyna' gibi bir yönerge verildiğinde çocuk yap-boz, bloklar ya da oyuncak kamyonu ile oynayabilir, ancak sözel yönerge verilmediğinde, model olunmadığında veya jest-mimik ipucu kullanılmadığında, sadece oyuncaklarının arasında durup hiç bir şeyle ilgilenmeyebilir. Benzer şekilde bisiklet sürmeyi, dişlerini firçalamayı, bilgisayarda oynamayı öğrenen çocuklar, aileleri veya öğretmenleri yönerge vermediği sürece bu becerileri sergilemekte genellikle güçlük çekerler. Dikkatli bir şekilde, sözel ipucu, bir cümleden tek sözcüğe, daha sonra da sadece beklenti ile bakışa kadar sistematik bir şekilde geri çekilmiş olsa bile, geri çekilmiş sözel ipucu ya da beklenti ile

bakış olmadan hedeflenen davranışlar ortaya çıkmaz, kısaca, uyaran kontrolü ipucundan etkinlikle ilgili çevresel uyaranlara transfer olmaz (MacDuff, Krantz, ve McClannahan, 1993; McGee, Krantz, Mason ve McClannahan, 1983; McClannahan ve Krantz, 2005). Yazının ilerleyen bölümünde etkinlik çizelgeleri için temel olan uyaran kontrolü, ipucu, ipucu bağımlılığı ve ipucu bağımlılığının nedenleri gibi kavramlar ayrı ayrı ele alınarak açıklanmıştır.

\section{Uyaran Kontrolü}

Davranış öncesi hedef uyaranın hedef davranışı ortaya çıarmasındaki sistematik etkisine uyaran kontrolü denilmektedir (Demchak, 1990; Etzel ve LeBlanc, 1979). Başka bir tanımda, hedef uyaranın varlığında hedef davranışın ortaya çıkma sıklığı, ipucu kullanılmadığı zamanlarda daha fazla ise davranışın uyaran kontrolü altında olduğu belirtilmiş̧tir (Ferster ve DeMyner, 1961; Gren, 1996; Terrace, 1963; Zygmont, Lazar, Dube ve Mcllvane, 1992).

Davranışın uyaran kontrolü altında olması durumu şu şekilde bir örnekle açıklanabilir: Birçok kişi için dergilerin ya da kitapların varlığı, okuma davranışını harekete geçirdiğinde okuma davranışının uyaran (dergilerin ya da kitapların varlığı) kontrolü altında olduğu söylenebilir. Ancak, okuma becerisi kazanmış otizmli bir çocuğun okuma davranışını genellikle kitap veya dergi gibi uyaranların varlı̆̆ harekete geçirmeyebilir. Okuma davranışını harekete geçiren, sözel ipuçları (Örn; 'Neden bir süre kitap okumuyorsun?') veya kitaplara ya da dergilere dikkati yöneltmeyi sağlayan jest-mimik gibi ipuçları (Örn; kitapları işaret etme) olabilmektedir. $\mathrm{Bu}$ durumda okuma davranışının uygun uyaranların kontrolü altında olduğunu söylemek mümkün olmayacaktır.

\section{İpucu}

Yardımcı ayırt edici uyaran olarak bilinen ipucu, hedef davranışın ortaya çıkma sıklığını arttırmaya yardımcı olması için sunulur. Yeni bir davranış öğretilirken, genellikle davranışı en sonunda kontrol eden uyaranın (ya da ayırt edici uyaranın) varlığında ortaya çıkan davranışın görülme sıklı̆̆ını arttırmak için ipuçları (yardımc1 uyaranlar) kullanılır (Krantz, MacDuff ve McClannahan, 1993; Lovaas, Ackerman, Alexander, Firestone, Perkins, Young, Carr ve Newsom, 1981; Lovaas ve Smith, 1989). Ancak bir önceki örnekte kitapların 
varlığında sözel bir ipucu (Örn;'Neden bir süre kitap okumuyorsun?') kullanılmasına gereksinim duyulmamalıdır, çünkü kitap okuma davranışını kitapların varlığı kontrol etmelidir.

\section{İpucu Bağımlılığı}

Otizmli bireylerin gelişimi ipucu bağımlılı̆̆ı yüzünden sık sık sekteye uğrar. Davranış kontrolü ipucundan uygun çevresel uyaranlara transferi başarısız olduğunda ipucu bağımlılığı gerçekleşir. Bu, uyaran kontrolünün sözel ipuçlarından ya da jest-mimiklerden çevresel uyaranlara transfer olmada belirgin bir şekilde başarısız olduğu anlamına gelmektedir (Johnson ve Sidman, 1993; Koegel, O’Dell ve Koegel, 1987). Örneğin; Legolardan model yapmayı öğrenen bir çocuk, annesi 'Hadi Legolarınla oyna' demeden Legolarıyla ilgilenmez. Gömleğinin düğmelerini iliklemeyi öğrenen bir çocuk, yapılması için öneride bulunana kadar gömleğini iliklemez. Yemek masasını hazırlamayı uzun süre önce öğrenen bir yetişkin, kendine hatırlatılana kadar masayı hazırlamaz (Krantz, ve diğ., 1993; Stromer ve Osborne, 1982).

\section{Ayrık Denemelerle Öğretim}

Ayrık denemelerle öğretim, alan yazında bilimsel dayanağı güçlü uygulamalar arasında yer alır. Ayrık denemelerle öğretimin alıcı dil, taklit, okuma gibi önemli birçok becerinin öğretiminde çok etkili olduğu bilimsel olarak kanıtlanmıştır. Ancak ayrık denemelerle öğretim sırasında çocukların sessizce bekleme ve etkileşimi sürdürme becerileri pekiştirildiği ve yanlışsız öğretim formatında kullanılsa bile ipucunu sunan kişi ortamdan kaldırılamadığı için ipucu bağımlılığını destekleme olasılığı yüksektir (Akgül, 2010; MacDuff ve diğ., 1993; Hall, 1997; McClannahan, MacDuff ve Krantz 2009; McClannahan ve Krantz, 2010). Ayrik denemelerle öğretim modelinde, öğretmen ya da aile bir yönerge verir ya da soru sorar, öğrenci tepki verir (ya da vermez), ödül kazanır (ya da kazanmaz) ve öğretmenin bir sonraki denemeye geçmesi için bekler. Çocuğun davranışları; beklemek, sözel ipucuna tepki vermek, ödül kazanmak ve bir sonraki deneme için tekrar beklemektir (Lovaas, ve diğ., 1981; Lovaas ve Smith, 1989). Davranış zinciri içinde pasif olarak bekleme, sürekli olarak ödüllendirilir ve bunun sonucunda çocuklar birilerinin onlara yönerge vermesini bekledikleri için daha az etkileşime girerler. Ancak ayrık denemelerle öğretimin bazı sözel taklit ve okuma gibi önemli becerilerin öğretiminde etkili olduğu da bilimsel olarak kanıtlanmıştır.

Etkinlik çizelgeleriyle ilgili araştırmalar yukarıda belirtilen bu ikilemden ortaya çıkmıştır. PCDI'da görev yapan uzmanlar bilimsel araştırmalar ile otizmli çocukların bisiklete binmek, yiyecek hazırlamak ve oyun oynamak gibi birçok beceriyi öğrenmelerine rağmen onlardan yapmaları istenmediği sürece bu becerileri sergilemediklerini kanıtlamışlardır. Bu çalışmalar araştırmacıları daha farklı öğretim yöntemleri üzerinde araştırmalar yapmaya yönlendirmiştir. (Krantz ve diğ., 1993; MacDuff ve diğ., 1993; McClannahan ve Krantz 1999). Uzmanlara göre eğer otizmli çocuklar etkinlik çizelgesi takip etmeyi öğrenebilirse (a) çocuklar çeşitli ortamlarda başkalarından ipucu almadan uyaranlara tepki verdiklerinde, günlük etkinlileri normal gelişim gösteren akranlarına daha benzer olabilecek, (b) aileler çocuklarını sürekli gözetim altında tutmak gibi çok stresli ve hayatlarını zorlaştıran durumlardan kurtulabileceklerdir (Krantz ve diğ., 1993; MacDuff ve diğ., 1993; McClannahan ve Krantz 1999; McClannahan ve Krantz, 2010).

\section{Etkinlik Çizelgesi Nedir?}

Etkinlik çizelgesi, bireyi bir dizi etkinliği yerine getirmeye yönlendiren fotoğraf ya da sözcük setidir (Akgül, 2010; MacDuff ve diğ., 1993; McClannahan ve Krantz, 1999; McClannahan ve Krantz, 2010). Etkinlik çizelgesi farklı şekillerde olabilir, ancak henüz okumayı bilmeyen çocuklar için etkinlik çizelgesi, başlangıçta, her sayfasında çocuğu etkinlikle meşgul olmaya ya da ödüllere yönlendiren fotoğraflı ipuçları bulunan dosyalardır. Çocuklar, etkinlik çizelgesini açmayı, ilk sayfayı çevirmeyi, fotoğrafı işaret etmeyi, resimde belirtilen materyali almayı, etkinliğini tamamlamayı, materyali yerine koymayı ve çizelgeye geri dönmeyi öğrenirler. Çocuklar çizelge takip etmede ustalaştıklarında ve okuma becerilerini geliştirdiklerinde, fotoğraflı ipucu yerine yazılı ipuçlarına tepki vermeyi öğrenirler. Örneğin, çocuk sayfayı çevirir, ipucunu işaret parmağıyla gösterir, ipucunu okur, etkinliği yerine getirir_ve etkinlik çizelgesine geri döner (McClannahan ve Krantz, 2010). 


\section{Etkinlik Çizelgesinin Avantajları}

Etkinlik çizelgelerinin, bağımsızlık, sosyal etkileşim ve seçim yapma gibi birçok avantajı bulunmaktadır. Aşağıda bu avantajlardan bazılarıyla ilgili açıklamalara yer verilmiştir.

Bă̆ımsızlık: Ekinlik çizelgesini takip etmeyi öğrenme, çocukları ipuçlarından ve sürekli bir gözetim ihtiyacından dolayısıyla ipucu bağımlılığından kurtarır. Araştırmalar, aynı zamanda çocukların kendi okullarında ve evlerinde etkinlik çizelgesi takip etmeyi öğrendikten sonra \%80-100 oranında zamanlarını etkinlikle meşgul geçirebildiklerini göstermektedir (Akgül, 2010; MacDuff di ̆. ., 1993). Krantz ve McClannahan, 1993 y1lında yayımladıkları araştırmalarında, etkinlikleriyle meşgul olmalarını artırmak amacıyla otizmli çocuklara çizelge takip becerisi kazandırmışlardır. Şekil-1'de görüldüğü gibi başlama düzeyi sırasında, içi boş siyah nokta ile gösterilen, etkinlikle meşgul olma düzeyi çok düşük seviyede; içi dolu siyah nokta ile belirtilen problem davranış gösterme düzeyi oldukça yüksek seviyede çıkmıştır. Ancak aileler çocuklarına etkinlik çizelgesi takip etmeyi öğrettikten sonra, çocukların etkinlikle meşgul olma düzeyleri yükselmiştir. Öğretim sona erdikten sonra da zaman içinde çocukların etkinlikleriyle meşgul olma düzeyleri yüksek çıkmaya devam etmiş,_ayrıca problem davranış gösterme düzeylerinde ise azalmalar olmuştur. Problem davranışların azalma nedeni olarak çocukların problem davranışları ile uyuşmayan olumlu davranışları öğrenmiş olmaları gösterilmiştir. Ayrıca araştırmada, problem davranışlarla başa çıkmak amacıyla başka bir müdahale yönteminin kullanılmadığı da belirtilmiştir.



Şekil 1. Etkinlik çizelgesi takip eden çocukların problem davranış ve etkinlikleriyle meşguliyet düzeyleri.

Seçim yapma: Yazılı ve fotoğraflı etkinlik çizelgeleri, otizmli bireylere seçim yapmayı kazandırmak amacıyla kullanılabilir. Dikkatli ve sistematik bir öğretim yapıldığında, çocuklar sadece etkinlik çizelgesi takip etmeyi değil, aynı zamanda tercih ettikleri etkinlikleri seçmeyi ve seçtikleri etkinlikleri sıraya koymayı da öğrenirler (Akgül, 2010; MacDuff ve diğ., 1993).

Şekil 2'de okul öncesi eğitim çağındaki bir çocuğun seçenekleri görülmektedir. Şekilde görüldüğü gibi, seçenekleri vagona binme, yiyecekler, içecek ve trampolinde zıplamadır. Başlangıçta, çocuklar 2 resim arasından seçim yapmayı öğrenirler; daha sonra resim ve seçeneklerin sayısı giderek artar. 


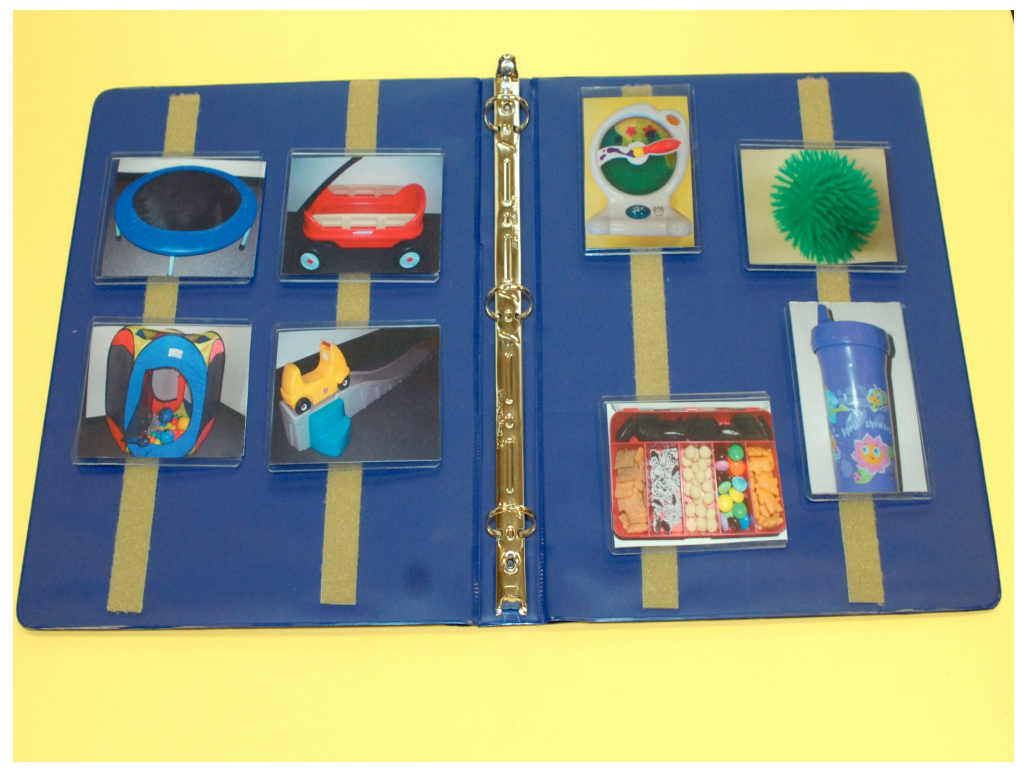

Şekil 2. Erken eğitim döneminde olan bir çocuğun fotoğraflı seçim panosu

Şekil 3'de, sözcük okumayı öğrenmiş bir çocuğun ödül panosundaki seçenekleri görülmektedir. Her çocuğun seçenekleri kendi tercih ettiği yiyecek, oyuncak ve etkinliklerden oluşur.



Şekil 3. Dokuz yaşında olan Uğur'un ödüllerinin yazılı olduğu seçim panosu

Sosyal etkileşim: Günlük etkinliklerimiz çoğunlukla konuşmayı gerektirmektedir. Ancak sosyal etkileşim, otizmli bireylerde en önde gelen problemler arasında görülmekte ve öncelikle ele alınması gereken bir konu olarak düşünülmektedir (Charlop ve Milstein, 1989; Haring, Kennedy, Adams ve Pitts-Conway, 1987). Bu nedenle, ilk etkinlik çizelgesi sosyal etkileşim gerektiren en az bir etkinlik içermelidir (Krantz ve McClannahan, 1993). Henüz konuşamayan bir çocuk, havaya hoplatılmak için birilerine yönelmeyi, bir kaç sözcük söyleyebilen bir çocuk ailesini ya da öğretmenini bulup 'gıdıklanmak' istediğini ifade ederek etkileşime girmeyi; cümle kuran 
bir çocuk ise tercih ettiği bir etkinlik hakkında talepte (Örn: 'Ben sallanmak istiyorum') bulunmayı öğrenebilir. Çocuklar çizelge takip becerisi kazandıklarında zaman içinde çizelgelerine akran etkileşiminin eklenmesi uygun görülmektedir (Krantz ve McClannahan, 1993).

Doğallık: Günlük yaşam içinde her insanın birçok sorumluluğu vardır ve birçoğu bu sorumlukları tam olarak yerine getirebilmek için çizelgeler, randevu defterleri, planlayıcılar ya da takvimler kullanırlar. Bazı kişiler 'Yapılacaklar' listesi hazırlarlar veya bazıları yapmak zorunda oldukları işleri takip etmek için tablet bilgisayarlar ya da cep telefonları kullanırlar. Fotoğraflı ve yazılı çizelgeler otizmli bireylerde tamamen aynı amaca hizmet etmektedir ve bu özelliği ile etkinlik çizelgeleri doğal bir yaklaşım olarak kabul edilmektedir. Çizelgeler otizmli bireylere yapmaları gereken işleri hatırlatırlar ve böylece onlar da diğer insanlar gibi başkalarının kendilerine yapmaları gerekenleri hatırlatmalarına ihtiyaç duymadan günlük rutinlerini ve etkinliklerini yerine getirirler (McClannahan ve Krantz, 2010).

\section{Etkinlik Çizelgesi Takip Etmeyi Öğretme}

Etkinlik çizelgesi takip etme becerisi, ipucu sunma ve ipucunu geri çekme ile öğretilir. İpucu sunma aşamasında elle yönlendirme; ipucunu geri çekme aşamasında ise aşamalı yardım, uzamsal geri çekme, gölge olma ve mesafeyi artırma kullanılır (Birkan, 2011; Akgül, 2010; McClannahan ve Krantz 1999). Yazının bu bölümünde ipucu sunma ve ipucunu geri çekme aşamaları ayrıntılarıyla açıklanmıştır.

\section{Elle Yönlendirme}

Etkinlik çizelgesi takip etme becerisi elle yönlendirme ile öğretilir. Elle yönlendirmede, eğitimci veya yetişkin eli ile çocuğun elinin üzerinden tutarak, çocuğun fotoğraflı ya da yazılı ipucunu işaret etmesini, materyalini almasını, etkinliğini tamamlamasını, materyalini kaldırmasını ve çizelgesine geri dönmesini öğretir. Elle yönlendirme bir yanlışsız öğretim yöntemidir ve daima çocuğun arkasından uygulanır (McClannahan, MacDuff ve Krantz, 2009). Elle yönlendirme tüm hataları önlemese de, hata olasılığını en az düzeye indirir. Hata olasılığını en az düzeyde tutmak çok önemlidir, çünkü hatalar ortaya çıkarsa, bazı çocuklar hatayı tekrar etmeyi öğrenirler ve bunun sonucunda doğru tepkileri öğretmek çok uzun zaman alabilir (Carr, Wilkinson, Blackman ve Mcllvane, 2000; MacDuff ve diğ., 1993; McClannahan ve Krantz, 1999; McClannahan ve Krantz, 2010). Şekil 4'de okul öncesi eğitim programına devam eden Ali, etkinlik çizelgesi takip ederken görülmektedir.

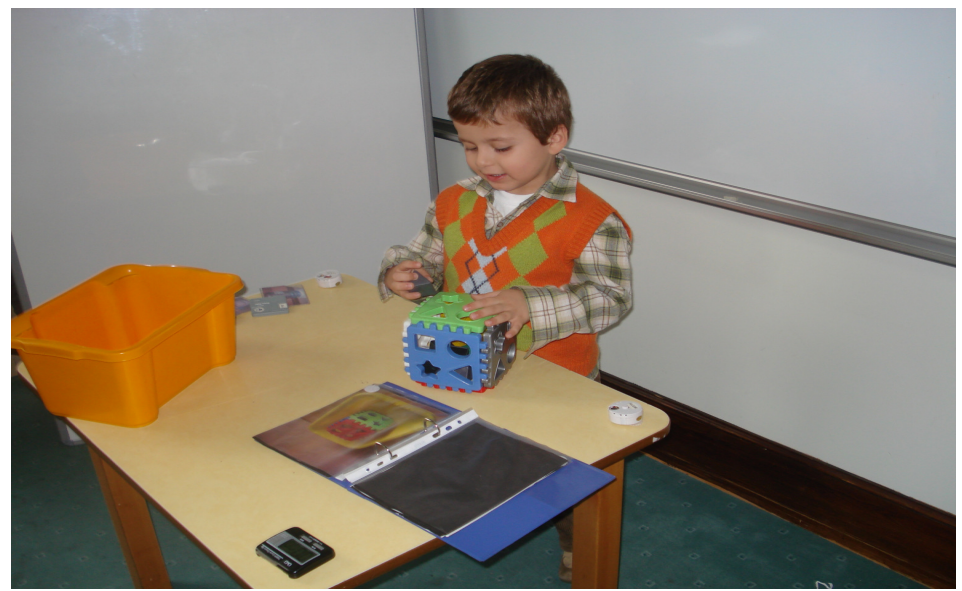

Şekil 4. Okul öncesi eğitim programına devam eden Ali fotoğraflı etkinlik çizelgesini takip ederken

\section{İpucunu Geri Çekme}

Çocuğun yeterliği arttıkça, yetişkin aşamalı yardım kullanarak elle yönlendirmeyi geri çeker. Destek olan yetişkinin elleri hala çocuğun ellerinin üstünde ya da çocuğun omuzlarının üstünde olsa dahi bu yardım daha az 
seviyededir. Bu yöntem genellikle ebeveynlere ve öğretmenlere oldukça yararlı bilgiler sağlar. Çocuğun el, kol ve vücut hareketlerine göre, yetişkin hızlı davranarak bir diğer adımda çocuğun doğru ya da yanlış bir tepkide bulunup bulunmayacağına karar verir ve yönlendirme yaparak hata yapmasını engeller ya da çocuğun doğru tepkilerine izin vererek etkinliği daha az yardımla bağımsız olarak yapmasını destekler.

Çocuklar çizelge takip etme becerisinin basamaklarını çok az yardımla yapabilir hale geldiğinde, yetişkin uzamsal geri-çekme kullanmalıdır. Yani ilk aşamada çocuğun elinin üstüne yapılan hafif dokunuşlar, bir süre sonra, çocuğun elinden bileğine, daha sonra kolunun ön kısmına ya da dirseğine ve sonra da omzuna ya da sırtına doğru geri kayar. Ancak eğer bir hata ortaya çıkarsa, yetişkin bir önceki ipucuna (Aşamalı yardım) geri dönmeli ve bu defa ipucuna çocuk bir kaç kez doğru tepki gösterinceye kadar devam edilmelidir (MacDuff ve diğ., 1993; McClannahan ve Krantz, 1999; McClannahan ve Krantz, 2010).

Uzamsal geri çekmeyi gölge olma takip eder. Bu aşamada, ipucunu sunan kişinin elleri, çocuğun hareketlerini takip eder ancak ona dokunmaz. İlk başta, yetişkin çocuktan bir kaç santimetre uzaklıkta gölge olabilir, eğer çocuğun tepkileri doğruysa, uzaklık giderek arttırılır. Yetişkin gölge olduğunda çocuk hata yapmıyorsa mesafeyi artırma zamanı gelmiştir. Çok küçük çocuklar için bunun anlamı, yetişkin aşamalı olarak bir metre uzaklaşır, daha sonra biraz daha uzaklaşır. Bazı çocuklar için ise ipucu sunan kişi etkinlik alanının öbür köşesinde, kapıda veya görünmeyecek şekilde başka bir yerde bekleyerek mesafeyi artırmak mümkün olabilir (MacDuff ve diğ., 1993; McClannahan ve Krantz, 1999; McClannahan ve Krantz, 2010). 
Tablo 1

Etkinlik Çizelgesi Takip Etme Becerisinin Öğretimi

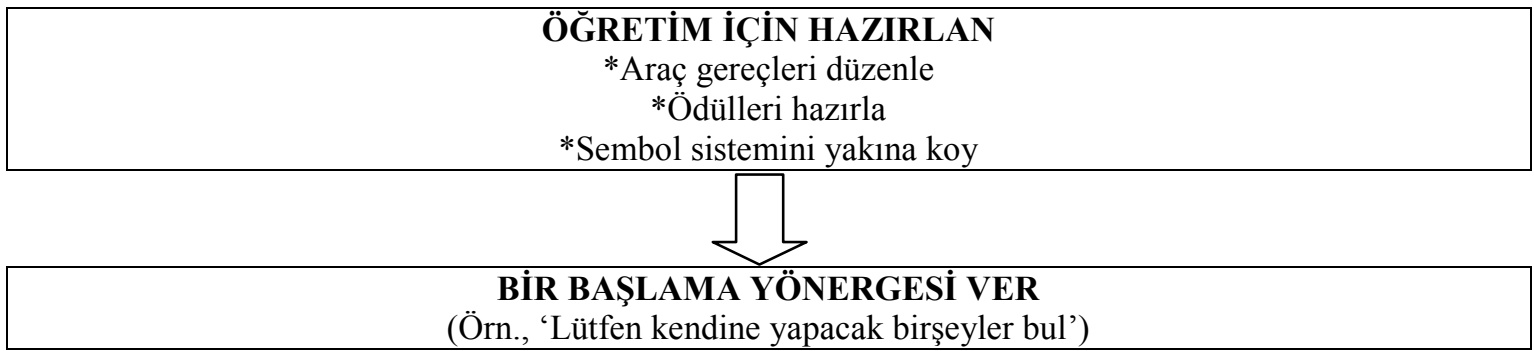



\section{ELLE YÖNLENDİRME KULLAN}

*Dosyayı aç veya sayfayı çevir

*Fotoğrafi işaret et

*Araç gereci al

*Etkinliği tamamla

*Araç gereci yerine kaldır
*Yiyecekleri arkasından ver

*Sembolleri arkasindan ver

*Sembolleri verirken görmesini sağla



HATALARI DÜZELT

*Bir önceki ipucunu geri çekme basamağına geri dön

*Çizelgeyi kapat ve oturuma yeniden başla

*Elle yönlendirmeye geri dön ve tüm çizelgeyi baştan sona yeniden öğret

*Ödüllerin etkililiğini gözden geçir

*Birçok defa hataya yol açan çizelgeyi değiştir

Kademeli olarak aşamalı yardımdan, uzamsal geri çekmeye, ondan da gölge olmaya ve mesafeyi artırmaya giden ipucu kullanma stratejilerine iриси sunma ve ipucunu geri çekme ile ögretim ya da azalan ipucu ile ögretim olarak adlandırılmaktadır (Heckamon, Alber, Hooper ve Heward, 1998; Sidman ve Tailby, 1982). Dikkatli bir şekilde yapılan ipucu sunma ve ipucunu geri çekme ile öğretim, çocuğun bağımsız olarak etkinlik çizelgesi izlemesini sağlar. Ancak çocuk hata yaptığında, yetişkin anında bir önceki ipucu sunma basamağına geri dönmelidir. Eğer çocuk gölge olma aşamasında hata yaparsa, yetişkin bu defa uzamsal geri çekme aşamasına geri dönmelidir. Eğer yetişkin uzamsal geri çekme kullanırken çocuk hata yaparsa, aşamalı yardıma 
geri dönmelidir. Ayrıca eğer hata, aşamalı yardım aşamasında ortaya çıkarsa, yetişkin bu defa elle yönlendirme aşamasına geri dönmelidir. Böylelikle daha fazla hatanın ortaya çıkması engellenmiş olur ve çocuğun bir sonraki tepkilerinde ödül kazanma olasılığı artar (Cooper, Heran ve Heward, 2007; Heckamon ve diğ., 1998). Tablo 1'de etkinlik çizelgesi takip etmenin öğretimi; Tablo 2'de ise öğretim sırasında yapılması ve yapılmaması gerekenler verilmiştir.

Tablo 2

Öğretim Sırasında Yapılması ve Yapılmaması Gerekenler

\begin{tabular}{|c|c|}
\hline Yap & Yapma \\
\hline - Araç gereci raflara veya kitaplıklara yerleştir & $\begin{array}{l}\text { •İlk çizelgenin öğretimini düzensiz dağınık bir } \\
\text { ortamda yapmaya çalış }\end{array}$ \\
\hline $\begin{array}{l}\text { - Kapı veya telefona cevap vermemek için } \\
\text { düzenleme yap }\end{array}$ & -Televizyonun veya diğer çocukların sesine canını sık \\
\hline - Araç gereci sıraya koy & -Çocuk ile araç gerecin arasına gir \\
\hline - Ödülleri önceden hazırla & •Bu ödülleri başka zamanlarda kullan \\
\hline - Başlama yönergesi ver & •Sosyal etkinliklerin dişında konuş \\
\hline - Elle yönlendirme kullan, hataları ve gecikmeleri & -İşaret et, mimik kullan, model ol veya çocuğun \\
\hline • Ödülleri sık kullan & • Ödülleri, çocuk geciktiğinde veya uygun olmayan \\
\hline
\end{tabular}

\section{Ödül Sistemini Programlama}

Çocuklara etkinlik çizelgesi takip etmeyi öğretmek, davranışa şekil verme yöntemidir. Ödüllendirilen davranışların gelecekte ortaya çıkma olasılığı yüksektir (Alberto ve Troutman, 2013; Buggey, Toombs, Gardener ve Cevretti, 1999; Cooper ve diğ., 2007). Her çocuğun değer verdiği ödülleri belirlemek önemlidir ve ödüller hedef davranışlara uygun olarak sunulmalıdır. Çok küçük yaştaki çocuklara etkinlik çizelgesi takip etmeyi öğretirken, ilk başta çocuğun çok sevdiği yiyecekler ödül olarak kullanılmalıdır. Çocuk, sayfayı işaret ettiğinde, materyali aldığında, etkinliğini yaptığında, materyalini yerine kaldırdığında ve çizelgesine geri döndüğünde yetişkin çocuğa yiyecek vermelidir. Daha sonra, çocuk doğru tepki verdiğinde yiyecekler bir bardağın içinde toplanabilir ve birkaç etkinliğini tamamladıktan sonra bardaktaki yiyecekler çocuğa sunulmalıdır. Çocuğun pekiştireç sunan yetişkine bağımlı kalmasını engellemek için çocuğa yiyecekleri arkasından sunmak önemlidir (McClannahan ve Krantz, 2010).

Mümkün olduğu kadar kısa süre içinde çocuklara sembol kullanımının öğretilmesinde büyük fayda vardır. Bunun için ilk başta, çocuk elle yönlendirme kullanılarak bir sembol karşılığı sevdiği yiyecekten bir parça kazanmayı öğrenebilir. Bunu bağımsız olarak yaptığında, bu defa iki sembol ile bir parça yiyecek kazanmayı öğrenebilir. Çocuklara giderek daha çok kazandıklarında sembollerini yiyecek, oyuncak ve etkinlik ödülleri ile değiş tokuş yapmak öğretilmelidir. Şekil 5'de örnek bir sembol tahtası görünmektedir. 


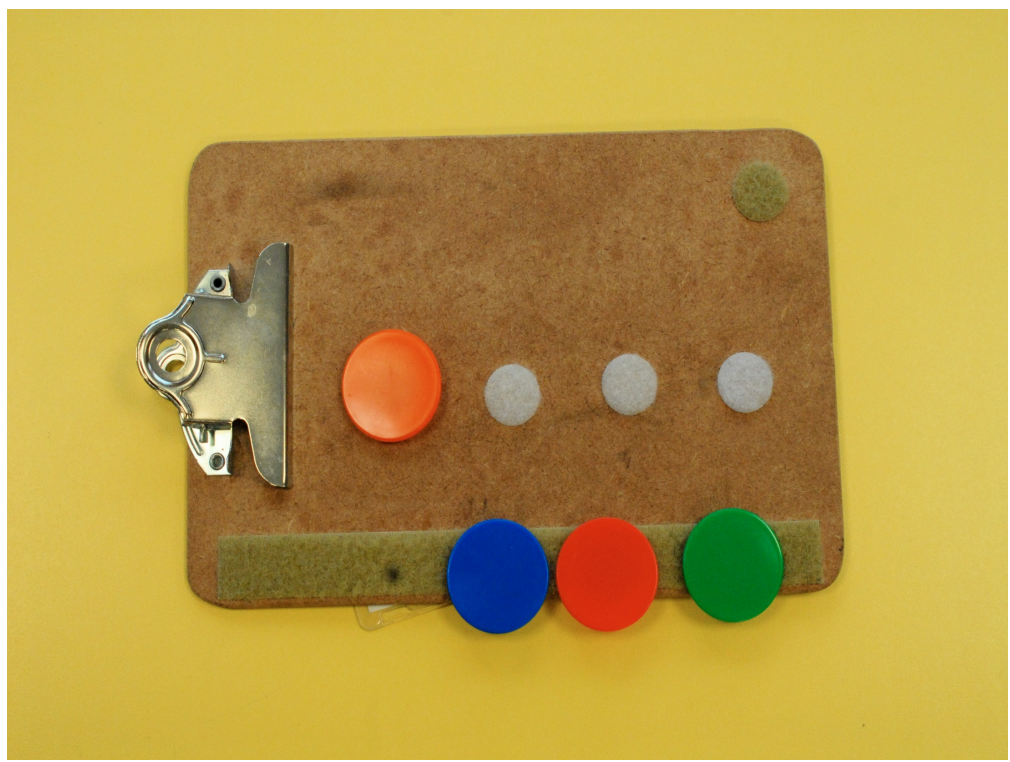

Şekil 5. Sembol tahtası

Sembol sisteminin öğretimine, etkinlik çizelgesi takip etme becerisinin öğretimi ile aynı anda başlamak yerine farklı zamanlarda ayrık denemelerle öğretim sırasında başlanmak daha etkili olacaktır. Sembol sistemi öğretilirken öğrencilere sembollerini tercih ettikleri oyuncakları ve etkinliklerle dönüştürmeleri hedeflenmelidir.

Ayrıca çocukların ödülleri etkinlik çizelgesine yerleştirilebilir. Örneğin bisiklete binmeyi seven bir çocuk, çizelgesinde sayfayı çevirir, bisiklet resmini işaret eder, bisikletin olduğu alana gider ve bisiklete biner veya öğrenci, etkinlik çizelgesinde bir bilgisayar resmi veya 'Bilgisayar' yazılı ipucunu görüp bilgisayarda oyun oynar.

\section{Etkinlik Çizelgesinin Kapsamı}

Etkinlik çizelgeleri bir saatliğine veya sadece okulda kullanılıp evde kullanılmayan bir materyal değildir. Çizelgeler, çocuğun tüm gününü organize etmek için kullanılabilir (Akgül, 2010; MacDuff ve diğ., 1993; McClannahan ve Krantz, 1999; McClannahan ve Krantz, 2010).

UDA bilimsel dayanağı güçlü birçok öğretim yöntemi sunar ve etkinlik çizelgeleri bu yöntemlerin birlikte kullanılmasına yardımcı olabilmektedir. Örneğin, çizelgelerle birlikte ayrık denemelerle öğretimi aynı anda uygulayabilmek için uygulama materyallerini işaret eden bir fotoğraf çizelgenin içine ipucu olarak yerleştirilebilir. Böylece ayrık denemelerle öğretimi uygulama zamanı geldiğinde çocuk çizelgesinde bulunan ipucunu işaret eder, ipucuyla ilişkili materyali alır, öğretmeniyle etkileşime girer ve ayrık denemelerle öğretim yapılır. Problem davranışlardan kaçınmak için ayrık denemelerle öğretim oturumları çok uzun sürelerle gerçekleştirilmemelidir. Bunun yerine, etkinlik çizelgesine aynı ipucundan birkaç tane yerleştirilmesi uygun olabilir, böylece gün içinde aynı etkinlik daha fazla sayıda kısa oturumlar halinde çalışılarak olası problem davranışlardan kaçınılması mümkün olabilecektir.

Çocuğun çizelgesine sevdiği bir oyuncağın resminin konulması çizelge aracılığıyla firsat öğretimi yapmaya olanak sağlayacaktır. Ancak bu durumda oyuncak çocuğun görebileceği fakat ulaşamayacağı bir yere 
yerleştirilmesi önemlidir. Böylece çocuk oyuncağı işaret ettiğinde ya da istediğinde, 'Yardım eder misin?' 'Yardım eder misin lütfen?' ya da 'O çok yüksek' demeyi öğretme firsatı yakalanmış olacaktır.

Ayrıca çocuğun çizelgesine yerleştirilen başka bir fotoğraf, video, VCD ve çeşitli materyalleri içeren bir kutuyu işaret edebilir. Çocuk fotoğrafın işaret ettiği kutuyu yerinden alıp öğretmenine götürdüğünde, öğretmeni elle yönlendirme kullanarak, videodan oyun taklit etmeyi öğretebilecektir.

Ekinlik çizelgeleri çocuklara aynı zamanda başkalarıyla sözel etkileşim başlatmayı ve sohbet etmeyi öğretirken de yardımcı olabilmektedir. Okuma bilen bir çocuğun etkinlik çizelgesine yazılı bir ipucu ilave edildiğinde, çocuk etkinlik çizelgesindeki ipucunu alıp, öğretmenine yaklaşarak ve repliğini söyleyerek sözel etkileşim başlatabilecektir. Yazılı ipucu daha sonra aşama aşama silikleştirilmelidir.

Etkinlik çizelgeleri aynı zamanda öğrencilerin sembolik oyun öğrenme ve oyunları hakkında konuşma becerisini kazandırmak için de firsatlar sunabilir. Etkinlik çizelgeleri, bir çok değişik etkinlik içerdiğinde (Örn., oyuncaklar, sözcük taklidi, banyo yapma, ve yemek yeme); günün farklı zamanlarında kullanıldığında (Örn., sabahları giyinirken, rakamları öğrenirken); farklı insanlarla çalışırken (aile ve öğretmen); ve farklı ortamlarda (Örn., okulda, evde, akrabaların, arkadaşların evinde) kullanıldığında daha etkili olacaklardır.

\section{Etkinlik Çizelgeleriyle Büyümek}

Çocuklar gelişim gösterdikçe, etkinlik çizelgelerinin içeriğinin çocukların yeni becerilerini yansıtacak biçimde düzenlenmesi ve her çocuğun yaşına uygun etkinliklere dönüştürülmesi gerekmektedir. Alan yazında çizelge takip becerisine sahip çocukların, gençlerin ve yetişkinlerin birden fazla fotoğraf veya ayrıntı yazılı ipuçları yerine tek bir fotoğraf veya yazılı tek sözcükten oluşan ipuçları ile çizelgelerini izleyebildikleri vurgulanmaktadır (McClannahan ve Krantz, 2010). Giyinme-soyunma becerisi için kullanılan ve birçok fotoğraftan oluşan etkinlik çizelgesinin yerine tek fotoğraftan oluşan bir ipucunun kullanılması bu aşama için örnek olarak verilebilir. Benzer bir biçimde sandviç yapma becerisinde ustalık kazanan bir öğrenci için başlangıçta verilen ayrıntılı ipuçları yerine (Ekmeği al, yağı al, reçeli al, fındık ezmesini al, bıçağı al), yalnızca 'Sandviç yap' gibi tek bir yazılı ipucunun verilmesi bu aşama için verilebilecek örneklerden birisidir.

Ayrıca alan yazın çocukların becerilerini geliştirmeye devam ettikçe, fotoğraflı veya yazılı etkinlik çizelgelerini kendi başlarına hazırlayabildiklerini belirtmektedir (McClannahan ve Krantz, 2010). Bu aşamaya bir örnek vermek gerekirse çizelge takibinde ustalaşan çocuklar her sabah etkinlik çizelgelerini alırlar, etkinliklerini sıraya koyarlar, eğer gerekiyorsa ortamlar arası uyarlama yaparlar ve yerine getirdikleri etkinlikler için çizelgelerine tik atarlar. Bu aşamaya gelmiş çocuklardan bu basamakları çoğunlukla yardım almadan bağımsız gerçekleştirebilmeleri beklenir. Yeni beceri setleri ile hedefe ulaşıldığında, etkinlik çizelgesine yeni etkinliklerin eklenmesi gerekmektedir. Alan yazında etkinlik çizelgelerinin değişken olduğu ve hedeflenen kıriterlere ulaşıldığında sürekli değiştirilmesi gerektiğinin üzerinde önemle durulmaktadır (McClannahan, MacDuff ve Krantz, 2009).

Etkinlik çizelgeleri birçok farklı becerinin öğretiminde kullanılan etkili öğretim araçlarıdır. Birkan, McClannahan ve Krantz (2007), yaptıkları bir çalışmada nesneleri adlandırma, sözel taklit ve fotoğraflı etkinlik çizelgesi takip etme becerilerine sahip, ancak sözcük okuma becerisi çok yavaş olan 6 yaşındaki otizmli Ej'e, yazılı etkinlik çizelgesi takip etmeyi öğretmek için, uyarana ipucu ekleme ve ipucunu silikleştirmeyle öğretim kullanmışlardır. Bunun için ilk önce sözcükler etkinlik çizelgesinde yer alan fotoğrafların üzerine yazılmış (Bakınız, Şekil 6), daha sonra arka planda kalan fotoğraflar sadece yazılar kalacak şekilde aşamalı olarak zamanla silikleştirilmiştir. Böylece bu yöntem ile EJ'in fotoğraflı etkinlik çizelgesinden yazılı etkinlik çizelgesine geçiş yapmasını sağlamıştır. 


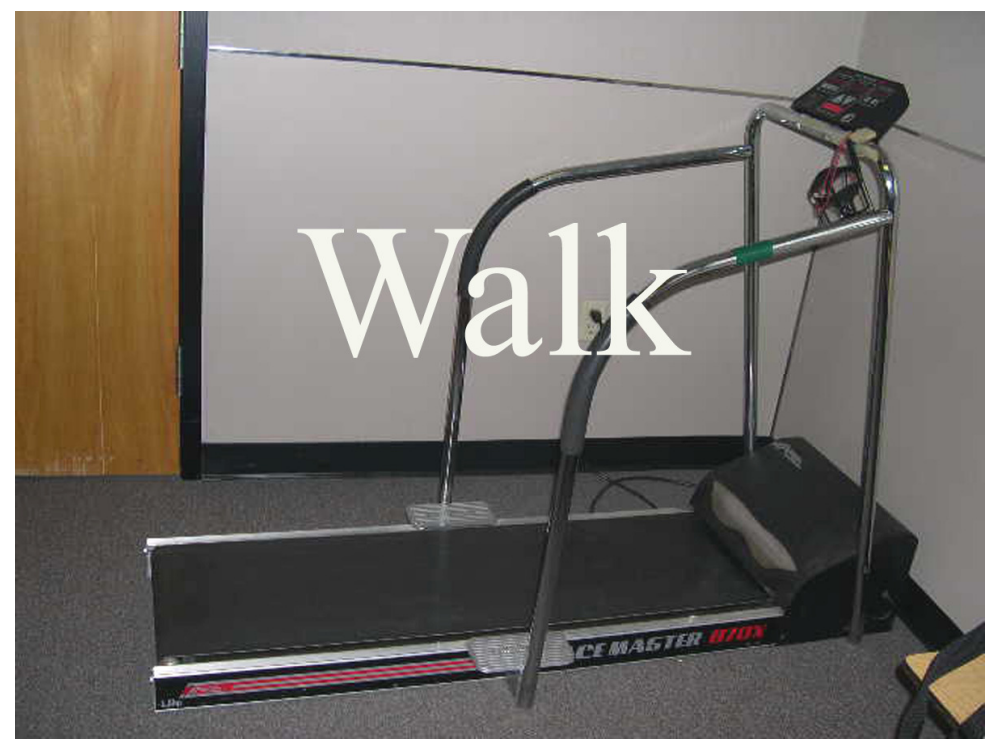

Şekil 6. EJ'in etkinlik çizelgesinde kullanılan uyaran ipucuna bir örnek

Bazı gençler için etkinlik çizelgeleriyle büyümek, cep telefonu, tablet bilgisayar, iTouch veya bir iPad üzerinde çizelge kullanmayı öğrenmek anlamına gelmektedir. Bu tür taşınabilir elektronik cihazlarda dijital fotoğraflar ve yazılar kolaylıkla gösterebilmektedir. Bu durumu bir örnek ile açıklamak gerekirse, okuma bilen bir çocuk çizelgesini bilgisayarından telefonuna nasıl aktaracağını öğrendiğinde taşınabilir bir elektronik cihazı kullanarak yazılı etkinlik çizelgesini takip edebilmektedir.

Bellovin, Burck, Tarnoski, Cammilleri ve Brothers (2003), el bilgisayarı üzerinde yazılı ve fotoğraflı etkinlik çizelgesi takip etme becerisi ile kağıt üzerinden yazılı ve fotoğraflı etkinlik çizelgesi takip etme becerisini karşılaştırmışlardır. Araştırmanın sonunda etkinlikle meşgul olma ve etkinliği tamamlama açısından iki yöntem açısından bir fark olmadığı ve her iki çizelgede de etkinlikle meşgul olma ve etkinliğini tamamlama oranlarının yüksek olduğu sonucuna varmışlardır.

\section{Yardımcı Çizelgeler}

Yazının bu bölümde bir özel eğitim okuluna devam eden öğrencilerin uygulamalarından bazı örnekler verilmiştir.

Örnek-1: Berke 10 yaşına yeni girmiş otizmli bir öğrencidir. Berke her okul gününe etkinliklerini seçerek, onları sıraya koyarak ve günlük ajandasına işleyerek başlar. Berke'nin ajandası aynı zamanda çizelgesidir ve bu ajanda onu diğer yardımcı çizelgelerine yönlendirir. Örneğin, günlük ajandası Berke'yi, matematik ödevine yönlendirir. Berke matematik ödevlerini ve bu ödevlerle ilişkili diğer çalışma kağıtlarının olduğu dosyayı raftan alır, masasına oturur ve etkinliğini tamamlar. Daha sonra, parmağını kaldırır ve öğretmeninden ödevini kontrol etmesini ister. Ödevini öğretmeni ile birlikte kontrol ettikten sonra, yerine kaldırır ve günlük ajandasında bu etkinliğin hemen yanına tamamladığına dair tik atar. Bazı günler, Berke'nin çizelgesinde, yiyecek hazırlamayla ilgili bir ipucu bulunur. Böyle durumlarda ise daha önceden öğrenmiş olduğu yemek tariflerinden oluşan çizelgeyi veya yapmayı yeni öğreneceği yemeğin beceri analizinden oluşan çizelgeyi kullanır.

Örnek-2: On üç yaşında otizmli bir öğrenci olan Kenan, son zamanlarda makarna yapmayı öğreniyor. Daha önceki yemek çizelgesinde yer alan bazı basamakları öğrendiği için artık bu basamaklar (Makarna poşetini 
açmak, makarnayı kaynatmak ya da karıştırmak gibi beceriler için artık ipucuna ihtiyaç duymuyor) yeni çizelgesinde yer almiyor.

Çocuklar yeni beceriler öğrenirken, sadece etkinlik çizelgeleri değil, aynı zamanda dönüştürülebilir sembol sistemleri de değiştirilerek yaşlarına uygun hale getirilmelidir. Özellikle okul çağındaki öğrenciler için sembol yerine demir paraların kullanımı önerilmektedir. Demir paraların kullanımının çocukların para sayma ve paraya değer verme gibi kavramları öğrenmelerine yardımcı olabileceği düşünülmektedir. Alan yazında bu tür becerilerin ergenlikte ve yetişkinlik dönemlerinde önemli olduğunun ve otizmli çocuklara özellikle öğretilmesi gerektiğinin altı çizilmektedir (MacDuff ve diğ., 1993; McClannahan ve Krantz, 1999; McClannahan ve Krantz, 2010).

Ödül panolarının da çocuklar büyüdükçe değiştirilmesi gerekmektedir. Oyuncakların küçük yaştaki çocuklar için uygun ödüller olduğu düşünülebilir ancak genç yetişkinler için bu tür uyaranlar uygun ödüller arasında yer almaz. Örneğin, 13 yaşındaki otizmli genç bir öğrenci sembol tahtasında bulunan sembollerinin tamamını kazandığında, bu sembolleri video izlemek, bilgisayar oyunları oynamak, dışarı çıkmak, müzik dinlemek gibi ödüller ile dönüştürebilir. Ödüllerin normal gelişim gösteren bir akranınki gibi hoşa giden etkinliklerden oluşmasının etkili bir öğretimde önemli bir yeri bulunmaktadır.

Çocuklar nasıl yapıldığını bilmedikleri etkinliklerle meşgul olmayı genelde tercih etmezler (Örn., Bisiklete binmek). Çocuğun henüz yaşantısında olmayan veya çok az deneyim firsatı bulduğu bu tür etkinliklerin birçoğu çizelgelere yerleştirilmelidir. Çocuklar bir müddet sonra nasıl yapıldıklarını öğrendiklerinde büyük olasılıkla bu etkinlikleri ödül olarak seçmeye başlayacaklardır.

Birçok genç yetişkin, etkinlik çizelgesini kendi cep telefonuna aktarmayı başarabilir. Öğrenciler günlük etkinlik çizelgelerini cep telefonlarına aktarmak için ayrıca bir yazılı çizelge kullanmayı öğrenebilirler. Öğrenciler aynı zamanda yazılı çizelge kullanarak e-posta göndermeyi ve daha sonra da gelen e-postalara cevap vermeyi de öğrenebilirler. Böylece farklı şehirlerde yaşayan kardeşleri, iş seyahatinde olan aile bireyleri ve eposta kullanmayı öğrenen başka akranları ile de yazışabilirler.

Etkinlik çizelgeleri ergenlik çağındaki çocukları yetişkinlik dönemine hazırlamak için kullanılabilecek etkili bilimsel uygulamalardır. Çizelgeler otizmli bireylerin uzun davranış zincirlerini tamamlama ve bu davranışları farklı ortamlara, kişilere, materyallere ve farklı zamanlara genellemede destek olabilirler. Aynı zamanda etkinlik çizelgeleri toplumsal yaşama ayak uydurma ve meslek edinmede önemli beceriler arasında sayılan seçim yapma, uygun etkinliklerle meşgul olma ve problem davranışları kontrol etmede becerilerinde de etkili olabilirler.

\section{Olası Sorunlar ve Olası Çözüm Önerileri}

Etkinlik çizelgesi takip etmeyi öğretirken birçok sorunla karşılaşmak mümkündür. Yaygın olarak karşılaşılan sorunların çözümünde kullanılabilecek stratejiler; (a) bir önceki ipucu yöntemine geri dönme, (b) kullanılan ödülleri gözden geçirme ve (c) davranış provası yaptırma şekilde sıralanmaktadır (Anderson, Sherman, Sheldon ve McAdam, 1997). Yapılan bilimsel araştırmalarda hem çocuklara, hem de yetişkinlere çizelge takibi kazandırırken bazı sorunlarla karşılaşıldığı ancak birçok eğitmen ve ailenin çizelge takibinin öğretiminde çok başarılı olduğu ve karşılaşılan problemlerin üstesinden gelebildikleri belirtilmektedir (Bellovin ve diğ., 2003). Ayrıca bu araştırmalarda etkinlik çizelgelerini planlamak, çocuklara kullanımlarını öğretmek, onları gözetim altında tutmayı sistemli olarak azaltmak ve böylece daha bağımsız ve verimli olmalarını sağlamak zaman ve çaba gerektirdiği belirtilmektedir. Aynı zamanda bilimsel araştırmalar anne-babaların ve eğitmenlerin etkinliklerden kaçan ve çeşitli problem davranışlar gösteren çocuklarını sürekli yönlendirmek için harcadıkları zamanı ve emeği etkinlik çizelgelerine harcayarak çocuklarına hayatları boyunca önem taşıyacak anahtar becerileri kazandırabileceklerini vurgulanmaktadır. 


\section{KAYNAKLAR}

Akgül, H. (2010). Otizmli çocuklara fotoğraflı etkinlik çizelgesi takip etme becerisi kazandırma. Yayınlanmamış yüksek lisans tezi. Marmara Üniversitesi, İstanbul.

Alberto, P.A., \& Troutman, A.C. (2013). Applied behavior analysis for Teachers, $9^{\text {nd }}$ ed. Upper Saddle River, N.J.: Pearson Prentice Hall.

Anderson, M.D., Sherman, J.A., Sheldon, J.B., \& McAdam, D. (1997). Picture activity schedule and engagement of adults with mental retardation in a group home. Research in Development Disabilities, 18, 231-250.

Baer, D.M., Wolf, M.M., \& Risley, T.R. (1968). Some current dimensions of applied behavior analysis. Journal of Applied BehaviorAnalysis, 1, 91-97.

Bellovin, E.R., Burck, S.E., Tarnoski, J.M., Cammilleri, A.P., \& Brothers, K.J. (2003). A comparison of the effects of textual activity schedules on paper versus textual activity of a personal data assistant (PDA). Poster presented at the Frst Annual Conference of the Princeton Child Development Institute, Princeton, NJ.

Bijou, S.V. (1996). Reflections on some early events related to behavior analysis of child development. The Behavior Analyst, 19, 49-60.

Birkan, B. (2011). Otizmli çocuklara konuşma becerilerinin öğretimi: Replikli öğretim. Ankara Üniversitesi Ĕ̈itim Bilimleri Fakültesi Özel Eğitim Dergisi, 12(1), 57-69.

Birkan, B., McClannahan, L.E., \& Krantz, P.J. (2007). Effects of superimposition and background fading on the sight-word reading of a boy with autism, Research in Autism Spectrum Disorders, 1(2007), 117-125.

Buggey, T., Toombs, K., Gardener, P., \& Cervetti, M. (1999). Training responding behaviors in students with autism: Using videotaped self-modeling. Journal of Positive Behavior Interventions 4, 205-214.

Carr, D., Wilkinson, K.M., Blackman, D., \& Mcllvane, W.J. (2000). Equivalence classes in individuals with minimal verbal repertoires. Journal of the Experimental Analysis of Behavior, 74, 101-114.

Cooper, J. O., Heron, T. E., \& Heward, W. L. (2007). Applied behavior analysis, $2^{\text {nd }}$ ed. Upper Saddle River, N.J.: Pearson Prentice Hall.

Charlop, M.H., \& Milstein, J.P. (1989). Teaching autistic children conversational speech using video modeling. Journal of Applied Behavior Analysis, 22, 275-285.

Demchak, M. (1990). Response prompting and fading methods: A review. American Journal on Mental Retardation. 94, 603-615.

Eikeseth, S., Smith, T., Jahr, E., \& Eldevik, S. (2002). Intensive behavioral treatment at school for 4- to 7-yearold children with autism: A 1-year comparison controlled study. Behavior Modification, 26, 49-68.

Eikeseth, S., Smith, T., Jahr, E., \& Eldevik, S. (2007). Outcome for children with autism who began intensive behavioral treatment between ages 4 and 7: A comparison controlled study. Behavior Modification, 31, 264-278

Etzel, B.C., \& LeBlanc, J.M. (1979). The simplest treatment alternative: The law of parsimony applied to choosing appropriate instructional control and errorless-learning procedures for the difficult-to-teach child. Journal of Autism and Developmental Disorders, 9, 361-382.

Ferster, C.B., \& DeMyer, M.K. (1961). The development of performances in autistic children in an automatically controlled environment. Journal of Chronic Diseases, 13, 312-345. 
Frost, LA., \& Bondy, A.S. (1994). The Picture Exchange Communication System Training Manual. Cherry Hill, NJ: Pyramid Educational Consultants, mc.

Green, G. (1996). Early behavioral intervention for autism: What does research tell us? In C. Maurice, G. Green, \& S. Luce (Eds.), Behavioral intervention for young children with autism: A manual for parents and professionals. Austin, TX: Pro-ed.

Hall, L.J. (1997). Effective behavioural strategies for the defining cha1acteristics of autism. Behavior Change, 4, 139-154.

Harin, T.G., Kennedy, C.H., Adams, M.J., \& Pitts-Conway, V. (1987). Teaching generalization of purchasing skills across community settings to autistic youth using videotape modeling._Journal of Applied Behavior Analysis. 20, 89-96.American children._Baltimore: Paul H. Brookes.

Heckamon, K.A., Alber,S., Hooper, S., \& Heward, W.L (1998). A comparison of least-to-most prompts and progressive time delay on the disruptive behavior of students with autism. Journal of Behavioral Education. 8,_171-201.

Howard, J., Sparkman, C., Cohen, H., Green, G., \& Stanislaw, H. (2005). A comparison of intensive behavior analytic and eclectic treatments for young children with autism. Research in Developmental Disabilities, 26, 359-383.

Koegel,R.L., O’Dell, M.C., \& Koegel, L.K. (1987). A natural language paradigm for teaching non-verbal autistic children. Journal of Autism and Developmental Disorders, 17, 187-199.

Krantz, P.J., MacDuff, M.T., \& McClannahan, L.E. (1993). Programming participation in family activities for children with autism: Parents' use of photographic activity schedules. Journal of Applied Behavior Analysis, 26, 137-138.

Krantz P.J., \& McClannahan, L.E. (1993). Teaching children with autism to initiate to peers: Effects of a scriptfading procedure. Journal of Applied Behavior Analysis. 26, 12 1-132.

Lovaas, O.I., Ackerman, A., Alexander, D., Firestone, P., Perkins, M., Young, D.B., Carr, E.G., \& Newsom, C. (1981). Teaching developmentally disabled children: The ME book. Austin,TX: PROED.

Lovaas, O.I., \& Smith, T. (1989). A comprehensive behavioral theory of autistic children: Paradigm for research and treatment. Journal of Behavior Therapy and Experimental Psychiatry, 20, 17-29.

MacDuff, G.S., Krantz, P.J., \& McClannahan, L.E. (1993). Teaching children with autism in use photographic activity schedules: Maintenance and generalization of complex response chains. Journal of Applied Behavior Analysis, 26,89-95.

McClannahan, L. E., \& Krantz, P. J. (2010). Otizmli çocukların eğitiminde etkinlik çizelgelerinin kullanımı. (Çev. B.Birkan) İstanbul: Sistem Yayınc1lık. (Orijinal eserin yayın tarihi 1999)

McClannahan, L. E., \& Krantz, P. J. (2010). Otizmli çocuklara konuşma becerilerinin öğretimi: Replikler ve replik silikleştirme.(Çev. B.Birkan) İstanbul: Sistem Yayıncılık. (Orijinal eserin yayın tarihi 2005)

McCannahan, L.E., \& Krantz, P.J. (1999). Activity schedules for children with autism: Teaching independent behavior. Bethesda, MD: Woodbine House.

McClannahan, L.E., MacDuff, G.S., \& Krantz, P.J. (2009). Activity schedule for adults with autism spectrum disorder. P. Reed (Eds.) Behavioral theories and intervention for autism. Nova Science Publishers, Inc. New York. 
McGee, G.G., Krtanz, P.J., Mason, D., \& McClannahan, L.E. (1983). A modified incidental-teaching procedure for autistic youth: Acquisition and generalization of receptive object labels. Journal of Applied Behavior Analysis, 16, 329-338.

Sidman, M., \& Tailby, W. (1982). Conditional discrimination vs. matching to sample: An expansion of the testing paradigm. Journal of the Experimental Analysis of Behavior, 37, 5-22.

Stromer, R., \& Osborne, J.G. (1982). Control of adolescents' arbitrary matching-to-sample by positive and negative stimulus relations. Journal of the Experimental Analysis of Behavior, 37, 329-348.

Terrace, H.S. (1963). Discrimination learning with and without errors. Journal of the Experimental Analysis of Behavior, 6,_1-27.

Zygmont, D.M., Lazar, R.M., Dube, W.V., \& Mcllvane, W.J. (1992). Teaching arbitrary matching via sample stimulus control shaping to young children and mentally retarded individuals: A methodological note. Journal of the Experimental Analysis of Behavior, 57, 109-117. 


\title{
Summary
}

\section{Activity Schedules: Teaching Independent, Choice and Social Interaction to Children with Autism}

\author{
Binyamin Birkan * \\ Tohum Autism Foundation
}

\section{What is an activity schedule?}

An activity schedule is a set of pictures or words that cues someone to engage in a sequence of activities (MacDuff, Krantz, \& McClannahan, 1993; McClannahan \& Krantz, 1999; McClannahan \& Krantz, 2010). An activity schedule can take many forms, but for young children and children who have not yet learned to read, it is initially a three-ring binder with pictures on each page that cue a child to engage in activities or enjoy rewards. Children learn to open their schedule books, turn to the first page, point to a picture, obtain the depicted materials, complete the activity, put materials away, and return to the schedule. As young people become skillful schedule followers and develop reading skills, they learn to respond to textual cues rather than photographs. After the child turns to this page, he points to and reads the text and then goes to the dining room and sets the table. When the table is set, he returns to his schedule (McClannahan \& Krantz, 2010).

\section{Advantages of Activity Schedules}

Independence: Learning to follow activity schedules helps children develop independence from prompts and independence from immediate, ongoing supervision. Our research, as well as our observation in preschool, school, and children's own homes, shows that after young people learn to follow schedules, they are typically on-task or appropriately engaged on $80 \%$ to $100 \%$ of time samples (Akgül, 2010; MacDuff, et al., 1993).

Choice: Photographic and written activity schedules provide a framework for helping young people with autism make choices. If we provide careful and systematic instruction, they not only learn to follow schedules, but they learn to choose their preferred activities and to choose the sequence of their learning activities. Initially, a child learns to make a choice when presented with only two pictures; then the number of pictures and the number of choices is gradually increased.

Social interaction: Pursuing our daily activities inevitably requires conversation. But social interaction is a key deficit for people with autism, and one that should be addressed as soon as possible (Charlop \& Milstein, 1989; Haring, Kennedy, Adams, \& Pitts-Conway, 1987). Therefore, even the first schedule for the youngest child should include at least one simple interaction task (Krantz \& McClannahan, 1993). A child who has not yet

\footnotetext{
*Assoc. Prof. Dr. Binyamin Birkan, Tohum Autism Foundation. Istanbul. E-mail: bbirkan@tohumotizm.org.tr
} 
acquired language may learn to approach someone for a toss in the air; a youngster who who now has a few words may seek out a parent or teacher and request "tickle"; and a boy or girl who uses sentences may request a preferred activity, for example, "I want swing." As children gain schedule-following skills, we also add peer interaction activities to their schedules.

Naturalistic: We are busy people. We have many commitments and most of us use schedules to help us accomplish our various responsibilities. We use appointment books, daytimers, planners, or calendars. We use "to do" lists, and some of us use electronic appointment books or hand-held computers to keep track of our obligations. Photographic and written schedules serve precisely the same function for young people with autism. Schedules remind them of the tasks that must be accomplished so that they, like us, need not depend upon other persons to instruct or "nag" about things that need to be done (McClannahan \& Krantz, 2010).

\section{Teaching Procedures}

\section{Manual guidance}

Manual guidance means that we provide hand-over-hand guidance to help a child point to a photographic or textual cue in his activity schedule, obtain the materials needed to do the activity, complete the activity, put materials away, and return to the schedule. Manual guidance is always delivered from behind the child (Carr, Wilkinson, Blackman, \& Mcllvane, 2000; MacDuff et al., 1993; McClannahan \& Krantz, 1999; McClannahan \& Krantz, 2010). Manual guidance is called an "errorless" procedure. Although it does not prevent all errors, it minimizes errors. This is important because if errors occur, some children may repeat them, with the result that it takes longer to teach the correct sequence of responses.

\section{Prompt fading procedures}

As a youngster displays increasing competence, the adult begins to fade manual prompts by using graduated guidance. Although the prompter's hands continue to be placed over the child's hands, less guidance is given. Typically, this procedure provides useful feedback to parents and teachers. On the basis of the child's hand, arm, and body movements, the adult can quickly determine whether the next response will be correct or incorrect, and can prevent errors by guiding, or promote independence by allowing correct responses to be completed with less assistance. (MacDuff et al., 1993; McClannahan \& Krantz, 1999; McClannahan \& Krantz, 2010).

When children complete all of the component schedule-following tasks with minimal guidance, the prompter uses spatial fading--that is, prompts in the form of light touches are initially delivered on the child's hands, and over a period of time, these touches are moved from his hands to his forearms, then to his elbow or upper arm, then to his shoulder or back. But if an error occurs, the adult returns to the previous prompting procedure--in this case, graduated guidance--until the child makes several correct responses (MacDuff et al., 1993; McClannahan \& Krantz, 1999; McClannahan \& Krantz, 2010).

Spatial fading is followed by shadowing. That is, the prompter's hands follow the child's movements, but without touching him. At first, the adult may shadow as closely as a few centimeters from the child, but if his responses are correct, the distance gradually increases.

When the adult shadows and the child makes no errors, it is time to decrease proximity. For very young children, this may mean that the adult gradually moves one meter away, then a little farther, and then a little farther still. For some children, it is possible to decrease proximity until the prompter is on the other side of an activity area, or just outside the nearest doorway, or out of sight.

The progression from graduated guidance to spatial fading to shadowing to decreased proximity is a prompt-fading sequence, or a most-to-least prompt hierarchy (Heckamon, Alber, Hooper, \& Heward, 1998; Sidman \& Tailby, 1982). Careful prompt fading enables a child to independently follow the activity schedule. But if the child makes an error, the adult immediately returns to the prior prompting procedure. If the adult was 
shadowing and an error occurs, she returns to spatial fading. If the adult was using spatial fading when an error occurred, she returns to graduated guidance until the child is again performing correctly. And if graduated guidance was used when an error was noted, the adult returns to full manual guidance. This helps to prevent additional errors and increases the likelihood that the child will receive rewards for his next responses (Heckamon et al., 1998).

\section{Programming Rewards}

Teaching children to follow activity schedules is a behavior shaping task. Responses that are followed by rewards are more likely to occur in the future (Buggey, Toombs, Gardener, \& Cevretti, 1999). It is important to select rewards that each individual child values and to provide rewards contingent upon the target performance.

When teaching very young children, we often begin by using a youngster's preferred snacks as rewards for schedule following. Standing behind the child, the adult provides small pieces of a snack when he points to a photograph, obtains materials, does the activity, puts materials away, and returns to his schedule. Later, snacks can be dropped in a cup when the relevant responses occur, and the child consumes the snack after completing only a few activities.

As soon as possible, we teach children to use tokens. Initially, the child is manually guided to exchange one token for one bite of a preferred snack. When he accomplishes this task without prompts, he earns two tokens and then exchanges for a reward. Gradually, he learns to earn more and more tokens before he exchanges them for a reward. When we first teach children to exchange tokens for snacks, toys, and activities, these skills are not taught at the same time that we teach schedule following. Instead, we teach token exchanges in separate, discrete-trial sessions. We want children to learn to exchange tokens for preferred toys and to exchange them for preferred activities.

It is especially important to embed rewards in children's activity schedules. For example, a child who enjoys bike riding turns a page of his schedule, points to a picture of a bike, goes to the location where the bike is kept, and rides the bike or a youngster finds a photo of a computer or the word "computer" in his schedule, and goes to play a computer game that he enjoys.

\section{Activity Schedules Provide a Framework for Instruction}

An activity schedule is not an intervention strategy that we use for an hour a day, or that we use only at school but not at home. Activity schedules are used to organize a child's entire day. They provide a framework for instruction (Akgül, 2010; MacDuff et al., 1993; McClannahan \& Krantz, 1999; McClannahan \& Krantz, 2010).

Applied behavior analysis offers many well-documented teaching procedures, and activity schedules help us to implement all of the instructional strategies that help children learn in many different ways. For example, a child's schedule may contain a picture of a bin that contains materials needed for a discrete-trial verbal imitation session. He points to the picture, obtains the materials, and then the teacher helps him learn to imitate target sounds or words.

Dorukan's schedule displays a picture of a favorite toy, but the toy is placed on a shelf beyond his reach. This sets the occasion for the instructor to do incidental teaching. When he initiates for the toy by pointing to it or requesting it, she will teach him to say "Help me" or "Help me, please" or "It's too high."

A photograph in his activity schedule may cue a child to obtain a box that contains a videotape and some toys. His teacher will play the video and, using and fading manual guidance, she will teach him to imitate responses modeled on the videotape. In this photograph, Jim is imitating a video model of feeding the doll. This curriculum will teach him to play appropriately with dolls and other toys. 
Activity schedules are also helpful when we teach children to engage in conversation. Because Ozan is a reader, he sometimes finds text on pages of his activity schedule. He removes the textual cue from his schedule, approaches a teacher, and initiates conversation by saying the phrase or sentence. The textual cues will later be faded.

Activity schedules may also set the occasion for children to engage in "pretend" play and to learn to talk about their play activities. Activity schedules are most effective when they cue many different types of activities (for example, imitating words, reading, playing with toys, bathing, and eating); when they are used at many different times of day (for example when getting dressed in the morning and when learning to identify numerals); when they are used with different people (for example, with parents as well as teachers); and when they are used in multiple settings (for example, at home, at school, and in friends' and relatives' homes).

\section{Growing Up with Activity Schedules}

As children develop, the content of activity schedules is modified to reflect their new skills, and to ensure that their activities are age-appropriate.

At Princeton Child Development Institute, all of the children, adolescents, and adults have schedulefollowing skills, and many activities that were once guided by multiple photographs or lengthy written task analyses are now cued by single pictures or words. For example, a schedule for getting dressed that originally contained many separate pictures was gradually condensed until now, dressing is cued by a single photograph of clothing. A schedule for making lunch was once a lengthy list (for example, get bread, get butter, get knife, get fruit...). Now, only the words "make lunch" appear in the adolescent's written schedule.

As they continue to develop skills, young people routinely manage their own schedules. They obtain their schedules at the beginning of each day, sequence their own activities, transport their schedules across settings, and turn pages or check off activities as they are completed, and they typically do these things without being prompted. When new skill sets are mastered, new activities are added; schedules are dynamic rather than static. Schedules are vehicles for many different teaching tasks (McClannahan, MacDuff, \& Krantz, 2009).

Six-year-old EJ learned to label many common objects, to imitate his teachers' verbal models, and to follow a photographic activity schedule, but his progress in reading was slow. His photographic activity schedule was used in conjunction with stimulus superimposition and background fading procedures, to help him learn to use written activity schedules In brief, text was superimposed on the photographs in the activity schedule and then the photographic backgrounds were faded until only the text remained in the schedule. These procedures helped EJ and many other children make the transition from photographic to written schedules (Birkan, McClannahan, \& Krantz, 2007).

For some youngsters, growing up with activity schedules means learning to use a schedule that is presented on a PDA or personal data assistant. Hand-held computers such as this Apple Palm Pilot can present digital photographs as well as text.

Research by Bellovin and his associates (2003) at the Somerset Hills Learning Institute in New Jersey compared children's performance when they used photographic and written schedules presented on paper versus schedules presented on hand-held computers. They found no differences in engagement or task completion. Both formats were associated with high levels of on-task and high rates of task completion.

\section{Sub-Schedules}

Berke, age 10, begins each school day by choosing the order of his activities and writing them in his daily planner. The planner is his main schedule; it refers him to many sub-schedules. For example, when the main schedule in his daily planner refers him to the Market Math curriculum, he obtains the notebook that contains his arithmetic assignment and the relevant worksheets, takes the materials to his desk, and completes the assignment. Then he raises his hand and asks his teacher to check his work. After he and the teacher review his 
answers, he puts the materials away, returns to his daily planner, and checks off the activity to show that it was completed. On some days, his schedule includes food preparation. He obtains the notebook that contains the recipes he has previously mastered and the task analyses of new foods he is learning to prepare.

Kenan is 10 years old years old and he is learning to make pasta. Some tasks that were in his previous foodpreparation schedules are no longer included in his new recipes, because he has acquired those skills. For example, he no longer needs separate written cues to open cans or to boil or combine ingredients.

As children develop new skills, not only their activity schedules change, but their token systems also change to become more age-appropriate. In this case, the tokens are coins. Using coins as tokens helps young people learn to count change and teaches them to value money. These are skills that are increasingly important in adolescence and adulthood.

Rewards also change as children grow up. Playing with toys is appropriate for younger children, but not for teenagers. A 13-year-old earns his tokens, he may choose to watch a video, play computer games, go outside, listen to music, or play catch. His reward activities are similar to those of typical adolescents.

None of us enjoys activities that are difficult or unfamiliar. Many of these activities were once a regular part of this youth's curriculum. After he practiced them and became fluent, he began to choose them as rewards. Many teenagers learn to add their own schedules to their hand-held devices. A 14-year-old uses this written schedule to add his daily schedule to his hand-held computer. He begins this schedule by connecting his handheld device to a desk-top computer and he continues to follow the written instructions in his schedule to add all of his daily activities to his hand-held computer. He has also learned to use e-mail. He uses this written schedule to read e-mail and then to reply. He carries on e-mail correspondence with his sisters who are away at college, with his father who often travels on business, and with other students who are also learning to use e-mail.

Activity schedules help young people prepare for adulthood. They help people with autism learn to complete lengthy response chains and they foster generalized responding to new activities. They provide a platform for making choices, they increase engagement with appropriate activities, and they decrease disruptive behavior. These skills are essential in preparing young people for employment and for community participation.

\section{More information about activity schedules}

Regardless of which intervention procedures we use, we sometimes encounter problems. Two common solutions to the problems we encounter when teaching children to follow schedules are first, return to the previous prompting procedure and second, reassess the rewards we are using. A third strategy is the use of behavioral rehearsals.

Many parents and teachers have experienced a great deal of success in teaching children to follow schedules and have surmounted problems that are sometimes encountered along the way. 
